\title{
Small-cell lung carcinoma with ovarian metastasis 4 years after the first-line treatment
}

\author{
Jun Kitazawa ${ }^{1}$ D $\cdot$ Akimasa Takahashi $^{1} \cdot$ Mao Uemura ${ }^{1} \cdot$ Yoshihiko Hayashi $^{1}$
}

Received: 22 August 2018 / Accepted: 14 February 2019 / Published online: 7 March 2019

(c) The Author(s) 2019

\begin{abstract}
Small-cell lung carcinoma rarely metastasizes to the ovary. Only few cases of this condition have been reported to date. A 42-year-old female nonsmoker was an outpatient after receiving treatment for small-cell lung carcinoma. Approximately 45 months after the first-line treatment, the pro-gastrin-releasing peptide level exhibited a gradual increase. Positron emission tomography-computed tomography revealed abnormal accumulation in the left ovary. Accordingly, we performed laparoscopic salpingo-oophorectomy. Both pathological and immunohistochemical examinations (thyroid transcription factor-1, synaptophysin, and chromogranin A staining) led to the diagnosis of ovarian metastasis of small-cell lung carcinoma. The pro-gastrin-releasing peptide level declined postoperatively, and no recurrence has been reported thus far. Here we reported an extremely rare case of small-cell lung carcinoma metastatic to the ovary after several years of receiving the initial treatment for small-cell lung carcinoma, which, however, exhibited an excellent course postoperatively.
\end{abstract}

Keywords Immunohistochemistry $\cdot$ Laparoscopic surgery $\cdot$ Ovarian diseases $\cdot$ Small-cell lung carcinoma

\section{Introduction}

Small-cell lung carcinoma (SCLC) is a type of lung cancer characterized by high proliferative ability and metastatic potential. Even in patients with SCLC eligible to receive the best treatment, $50 \%$ experience recurrence within the first year [1]. SLSC recurrence has been typically reported in organs, such as the brain, liver, lung, and bone. However, its metastasis to the ovary is a sporadic occurrence, and an extensive literature search revealed only few such documented cases. Here, we present a unique case of a patient with SCLC with ovarian metastasis 4 years after receiving the first-line treatment but exhibited good results with surgical treatment.

\section{Case report}

Patient: A 42-year-old female nonsmoker. BMI: $26.6 \mathrm{~kg} / \mathrm{m}^{2}$.

Jun Kitazawa

jk110530@belle.shiga-med.ac.jp

1 Department of Obstetrics and Gynecology, Nagahama City Hospital, 313 Oinui-cho, Nagahama, Shiga 526-8580, Japan
Medical history: nothing in particular.

Clinical course: She was referred to the Thoracic Surgery Department of Nagahama City Hospital because of an abnormal chest X-ray radiograph (left pulmonary hilar nodule, 3-cm diameter). A bronchoscopic biopsy revealed SCLC (LD: c-T2aN1M0; Stage IIA, Fig. 1a). However, her metastatic workup was negative, which comprised cranial magnetic resonance imaging (MRI) and bone scintigraphy. Accordingly, combined treatment with chemotherapy $\left[60 \mathrm{mg} / \mathrm{m}^{2}\right.$ cisplatin (day 1 ) $+60 \mathrm{mg} / \mathrm{m}^{2}$ irinotecan (days 1 , 8 , and 15)] and radiotherapy (total $36 \mathrm{~Gy}$ ) was initiated, followed by thoracoscopic lobectomy 3 weeks after last chemotherapy (Fig. 1b). Immunohistochemical findings of lung tissue are shown in Fig. 1c-e. Of note, the surgical stage was yp-T1N0M0: Stage IA.

Figure 2 shows the postoperative course. Nearly 4 years after receiving the first-line treatment, the pro-gastrin-releasing peptide (ProGRP) level exhibited a gradual increase. The patient underwent additional chemotherapy with amrubicin alone $\left[45 \mathrm{mg} / \mathrm{m}^{2}\right.$ (day $1,2,3$ ), cisplatin + etoposide [80 mg/ $\mathrm{m}^{2}$ cisplatin (day 1 ) $+100 \mathrm{mg} / \mathrm{m}^{2}$ etoposide (day $1,2,3$ )], and carboplatin + irinotecan [AUC5 carboplatin (day 1) $+50 \mathrm{mg}$ / $\mathrm{m}^{2}$ irinotecan (day 1, 8, 15)]. Despite this treatment, the ProGRP level did not decrease. Positron emission tomography-computed tomography (PET-CT) revealed an abnormal 
Fig. 1 Histological and immunohistochemical findings of the left lower lung lobe. a Biopsy tissue: dense growth of heterotypic cells with high $\mathrm{N} / \mathrm{C}$ ratio is observed. Lesions forming irregular alveolar lamina and nuclear chromatin are relatively uniform; nucleoli are not noticeable (H\&E staining, $\times 40)$. b Surgical sampling: invasive proliferation of heterozygous cells with a high $\mathrm{N} / \mathrm{C}$ ratio is observed in the region, showing a nodule-like shape microscopically. Nuclear chromatin is in the form of fine granules, and nucleoli are not noticeable (H\&E staining, $\times 20)$. Immunoreactivity of tumor cells with antibodies to TTF-1 (c immunostain, $\times 40$ ), synaptophysin (d immunostain, $\times 40)$, and chromogranin A (e immunostain, $\times 40$ )
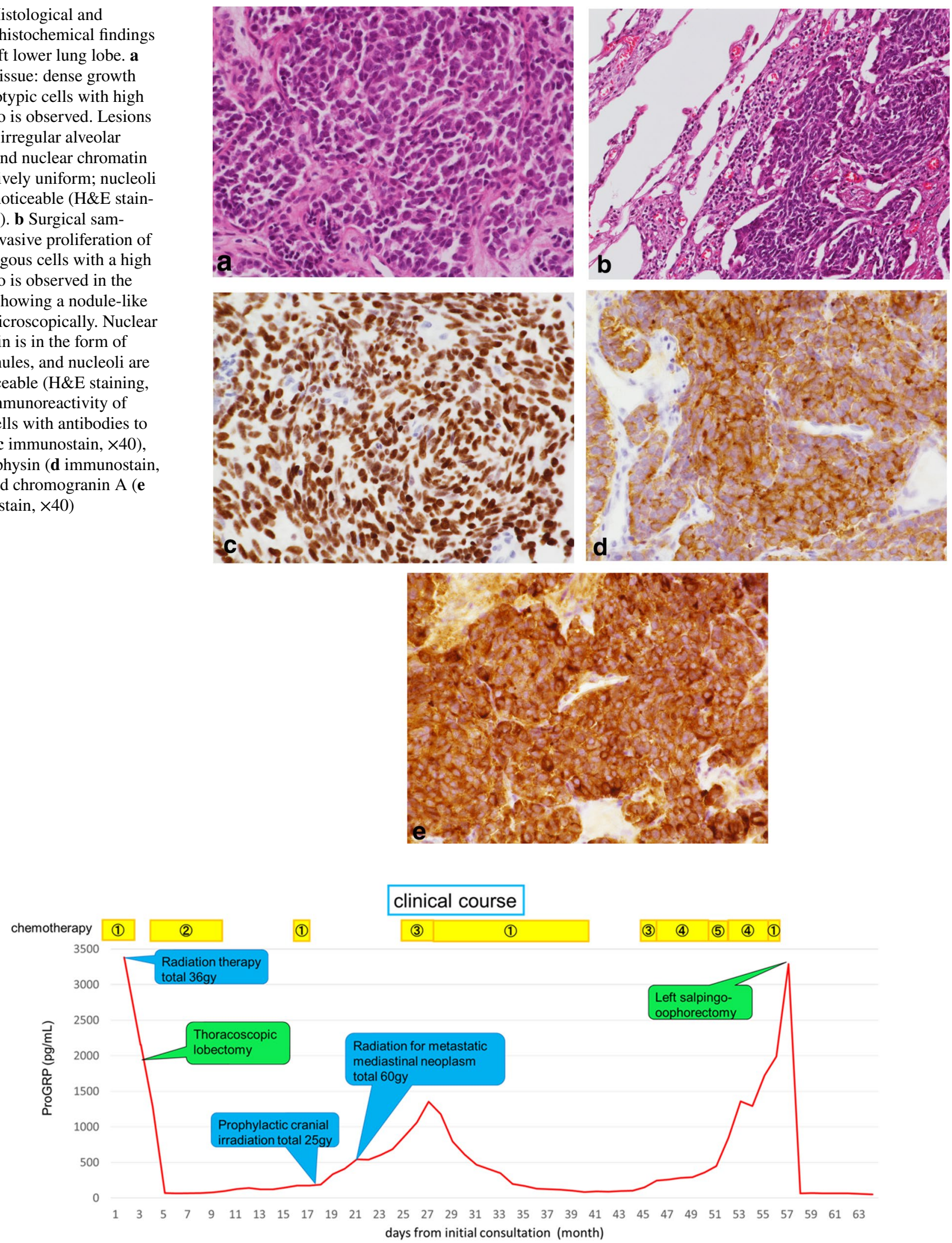

(1)CDDP: $60 \mathrm{mg} / \mathrm{m}^{2}$ day 1 + CPT-11: $60 \mathrm{mg} / \mathrm{m}^{2}$ day1, 8, 15 (2)CBDCA: AUC5 day 1 + VP-16: $100 \mathrm{mg} / \mathrm{m}^{2}$ day $1,2,3$

(3)AMR: $45 \mathrm{mg} / \mathrm{m}^{2}$ day1, 2, 3 (4)CDDP: $80 \mathrm{mg} / \mathrm{m}^{2}$ day1 + VP-16: 100mg $/ \mathrm{m}^{2}$ day1, 2, 3 (5)CBDCA: AUC5 day1 + CPT-11: 50mg/m² day1, 8,15

Fig. 2 Clinical course from the initial consultation. Approximately 4 years after the first visit, the ProGRP level registered a gradual increase. After surgery, the ProGRP level dramatically declined 


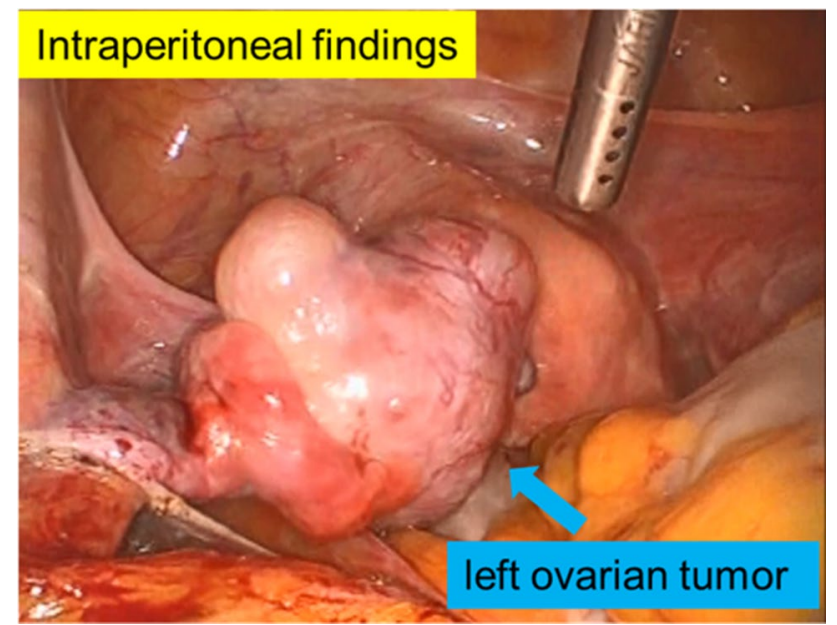

Fig. 3 Intraperitoneal findings during surgery. The left ovary was enlarged to $4 \mathrm{~cm}$ (blue arrow). The external surface was smooth and formed bumps

accumulation in the left ovary. In addition, pelvic MRI revealed a solid tumor in the left ovary with an uneven contrast effect. Accordingly, she was referred to the Obstetrics and Gynecology Department.

We performed laparoscopic salpingo-oophorectomy 3 days after she visited our hospital. The left ovary had enlarged to $4 \mathrm{~cm}$, and the external surface was smooth and formed bumps (Fig. 3). There was no other metastatic site. Figure 4 shows the pathological histology of the left ovarian tumor. In addition, all immunohistochemistry results for thyroid transcription factor-1 (TTF-1), synaptophysin, and chromogranin A were positive (Fig. 5); these immunohistochemical test results have also been found to be positive in

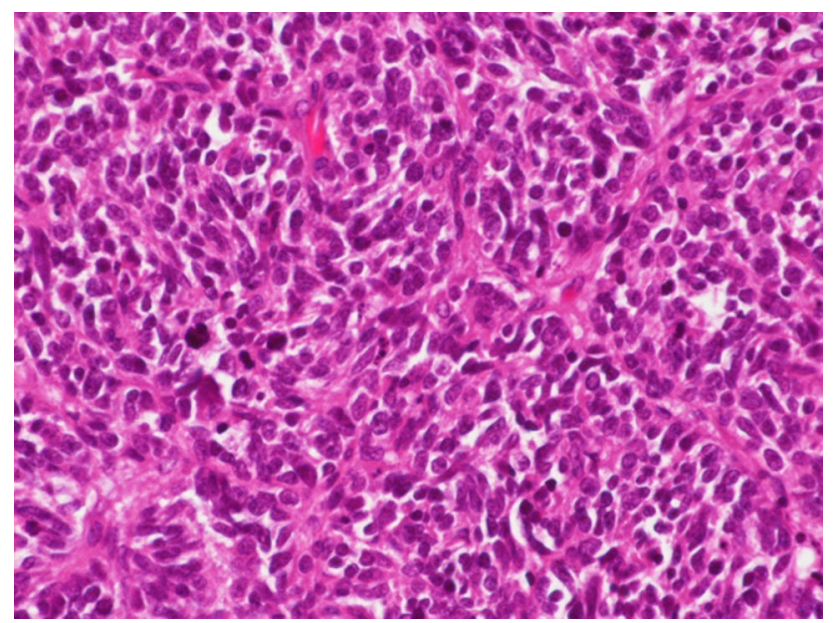

Fig. 4 Histological findings of the left ovarian tumor. An irregular alveolar growth pattern of heterotypic cells with a high $\mathrm{N}: \mathrm{C}$ ratio. Nuclear chromatin was present in fine granular form. The rosette sequence was suspected in part (H\&E staining, $\times 40)$
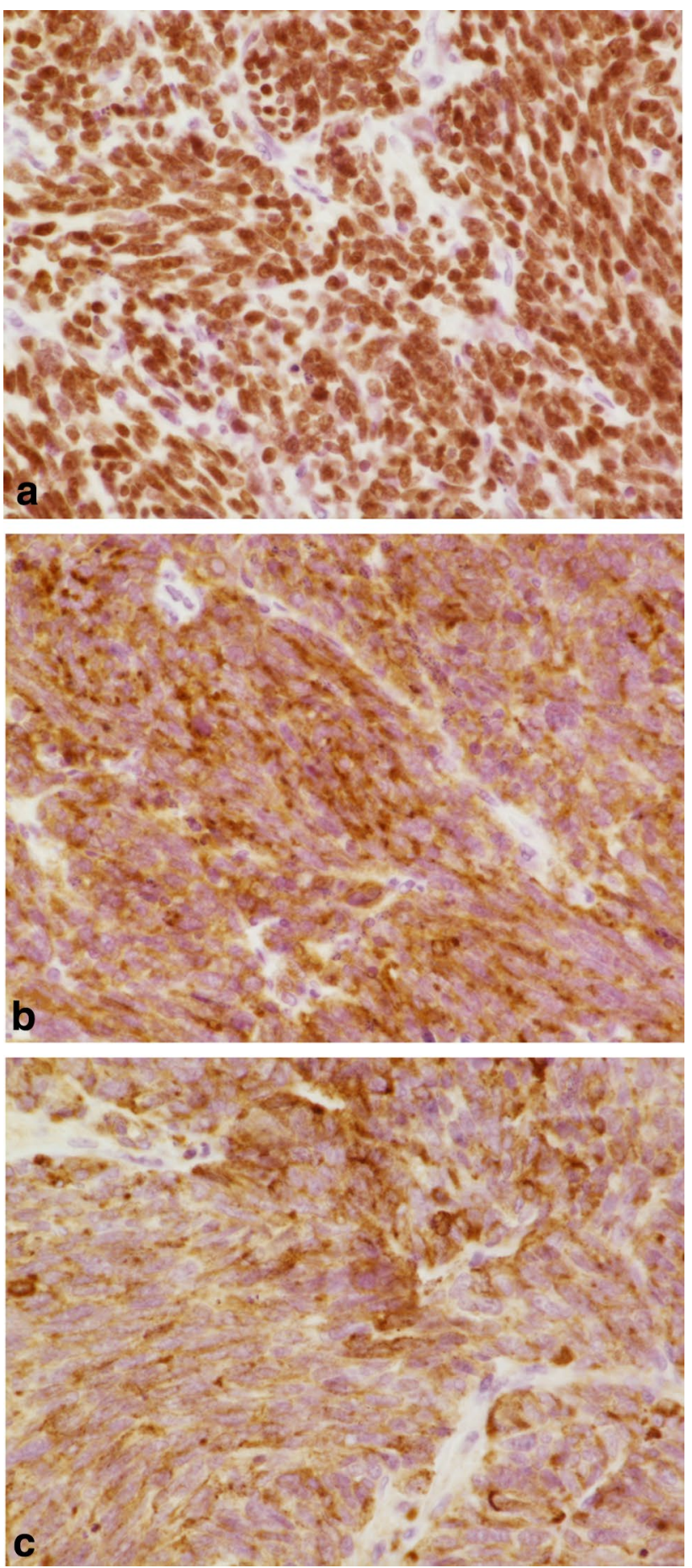

Fig. 5 Immunohistochemical findings of the left ovarian tumor. Immunoreactivity of tumor cells with antibody to TTF-1 (a immunostain, $\times 40$ ), synaptophysin (b immunostain, $\times 40$ ), and chromogranin A (c immunostain, $\times 40)$

lung tumor tissue (Fig. 1). These findings were consistent with metastatic SCLC in the ovary. Postoperatively, as the ProGRP level markedly decreased, we did not perform any 
additional treatment. 11 months after this recurrence, her carcinoma has not relapsed.

\section{Discussion}

SCLC is a type of lung cancer that is known to recur in various organs of the body, including the brain, liver, lung, and bone. However, its metastasis to the ovary is a rarely reported event; therefore, only few studies have reported such cases to date. In addition, to the best of our knowledge, no study, to date, has reported a successful case of surgical treatment of ovarian metastasis of SCLC. Thus, this report presents a unique case.

Studies have revealed that SCLC is very aggressive, and metastases to the lymph nodes and distant organs have already been recognized at its diagnosis. However, the frequency of ovarian metastasis from primary lung carcinoma, including SCLC, is very low (0.4\%) [2]. Table 1 summarizes cases of ovarian metastasis of SCLC [1-6]. In these cases, ovarian metastasis was detected several months after the diagnosis of SCLC. However, in our case, ovarian metastasis occurred after a prolonged period of 57 months after receiving the first-line treatment. To date, no case of ovarian metastasis this long after SCLC treatment, like our case, has been reported. SCLC is a type of cancer that is synonymous with poor prognosis. The overall 2-year survival is reported to be only $21 \%$ in treated patients, whereas untreated patients have a median survival of 3 months since diagnosis [7]. Our patient survived for an exceptionally long period, which might have resulted in ovarian metastasis from SCLC.

Differentiating between ovarian metastasis of SCLC and primary ovarian small-cell carcinoma is challenging as both present similar histological and immunohistochemical findings. Typically, TTF-1, synaptophysin, and chromogranin A tend to test positive for small-cell carcinoma of any organ other than the lung. Although the standard treatment for small-cell lung cancer has been established, a treatment protocol for primary ovarian small-cell carcinoma, which has worse prognosis, has not yet been established. Hence, comprehensive assessment of the whole body to confirm the presence of tumors in other organs, such as lungs, is imperative to differentiate between these conditions.

Regarding pathological differential diagnosis of this case, adult-type granulosa cell tumor, primitive neuroectodermal tumor (PNET), and desmoplastic small round cell tumor can be mentioned. The diagnosis for adult type granulosa cell tumor was considered negative because immunostaining was positive for chromogranin A, synaptophysin, and TTF1; nuclear furrows could not be confirmed; and many fissile images were observed in the H\&E staining. The diagnosis for PNET was considered negative because of H\&E staining, poor homogeneity in tumor cells, and nuclear chromatin not being delicate. Also, it was difficult to believe that PNET was rarely generated in ovaries. The desmoplastic small round cell tumor was considered negative because no remarkable interstitial reaction was observed.

In our case, surgical resection of this chemotherapyresistant ovarian metastasis resulted in a remarkable decrease in tumor marker levels. Usually, recurrent SCLC is treated with chemotherapy, and the antitumor effects of subsequent chemotherapy depend on the period from the initial treatment to recurrence. Some studies have reported that the response rate of chemotherapy is significantly higher in prolonged cases with a period of 60-90 days or longer before recurrence $[8,9]$. Johnson et al. reported that regarding the response rate of oral etoposide against recurrent SCLC, the number of patients who relapsed after $>90$ days was $64 \%$, whereas those who had $<90$ days from the end of initial treatment were $12.5 \%$ [9]. In our case, however, nearly 60 days had passed since the last chemotherapy to recurrence, and additional chemotherapy had failed. The findings of our case suggest that despite no benefit of surgical treatment for

Table 1 A summary of published reports of SCLC with ovarian metastasis

\begin{tabular}{|c|c|c|c|c|}
\hline Author (year) & Age & $\begin{array}{l}\text { Time from treatments } \\
\text { of lung cancer (month) }\end{array}$ & Situs of metastases excluding ovaries & Immunohistochemistry \\
\hline Present case & 42 & 57 & Anterior mediastinum & $\begin{array}{l}\text { TTF-1, synaptophysin, and chro- } \\
\text { mogranin A positive }\end{array}$ \\
\hline Moro F (2017) & 24 & 0 & No site & No shown \\
\hline Garcia V (2010) & 54 & 3 & $\begin{array}{l}\text { Lymph nodes in the subcarinal, left } \\
\text { hilus and left supraclavicular, cen- } \\
\text { tral nerve system }\end{array}$ & $\begin{array}{l}\text { Synaptophysin, chromogranin A and } \\
\text { p53 positive }\end{array}$ \\
\hline Irving JA (2005), 14 cases & $46(26-71)$ & $2.2(0-12)$ & $\begin{array}{l}\text { Various sites (bone, liver, mediasti- } \\
\text { num etc.) }\end{array}$ & TTF- 1 positive in 4 out of 6 cases \\
\hline Bing Z (2005) & 62 & 0 & No site & TTF-1 and chromogranin A positive \\
\hline Sukumvanich P (2005) & 42 & 12 & Brain & No shown \\
\hline Malviya VK (1982) & 40 & 0 & No site & No shown \\
\hline
\end{tabular}


metastasis of SCLC, it is a curative treatment option if the metastatic lesion is localized.

She was young and a non-smoker, and she did not have any risk factors for SCLC, such as family history or environmental factors. SCLC is rare in non-smokers. In an epidemiologic study performed in the USA, only $2.5 \%$ of all SCLC cases were diagnosed among non-smokers [10]. In our case, the reason for the long-term course remains unclear. However, we hypothesize that chemotherapy played a role in delaying the progression of the disease, although it cannot prevent recurrence. On the other hand, it is possible that cancer cells resistant to chemotherapy may have been dormant for a long time. Clinical evidence of cellular dormancy has been documented in both primary tumor and metastases, and it has also been suggested that dormant cells can be refractory to treatment [11]. Because there are few cases on long-term survival of small-cell lung cancer, it is necessary to further accumulate and examine such cases in the future.

In conclusion, we reported an extremely rare case of ovarian metastasis of SCLC after several years of receiving the initial treatment. Successful treatment of this case highlights that surgical treatment could be a potential treatment option for localized metastatic lesions that are resistant to chemotherapy.

\section{Compliance with ethical standards}

Conflict of interest The authors declare that they have no conflict of interest.

Ethical approval For this type of study, formal consent is not required.

Informed consent Informed consent was obtained from all individual participants included in the study.

Open Access This article is distributed under the terms of the Creative Commons Attribution 4.0 International License (http://creativeco mmons.org/licenses/by/4.0/), which permits unrestricted use, distribution, and reproduction in any medium, provided you give appropriate credit to the original author(s) and the source, provide a link to the Creative Commons license, and indicate if changes were made.

\section{References}

1. Sukumvanich P, Einstein M, Wagner B et al (2005) Recurrent small cell lung cancer presenting as bilateral adnexal masses. Gynecol Oncol 96:232-234

2. Irving JA, Young RH (2005) Lung carcinoma metastatic to the ovary: a clinicopathologic study of 32 cases emphasizing their morphologic spectrum and problems in differential diagnosis. Am J Surg Pathol 29:997-1006

3. Moro F, Mascilini F, Casella E et al (2017) Small cell lung cancer metastatic to the ovary diagnosed during pregnancy. Ultrasound Obstet Gynecol 50:802-803

4. Garcia V, Velasco A, Gatius S et al (2010) Pulmonary small cell carcinoma metastatic to the ovary: a clinicopathologic study of one case with emphasis on the importance of p53 analysis in diagnosis. Gynecol Obstet Investig 70:87-90

5. Bing Z, Adegboyega PA (2005) Metastasis of small cell carcinoma of lung into an ovarian mucinous neoplasm: immunohistochemistry as a useful ancillary technique for diagnosis and classification of rare tumors. Appl Immunohistochem Mol Morphol 13:104-107

6. Malviya VK, Bansal M, Chahinian P et al (1982) Small cell anaplastic lung cancer presenting as an ovarian metastasis. Int J Gynaecol Obstet 20:487-493

7. Zelen M (1973) Keynote address on biostatistics and data retrieval. Cancer Chemother Rep 4:31-42

8. Batist G, Carney DN, Cowan KH et al (1986) Etoposide (VP-16) and cisplatin in previously treated small-cell lung cancer: clinical trial and in vitro correlates. J Clin Oncol 4:982-986

9. Johnson DH, Greco FA, Strupp J et al (1990) Prolonged administration of oral etoposide in patients with relapsed or refractory small-cell lung cancer: a phase II trial. J Clin Oncol 8:1613-1617

10. Ou SH, Ziogas A, Zell JA (2009) Prognostic factors for survival in extensive stage small cell lung cancer (ED-SCLC): the importance of smoking history, socioeconomic and marital statuses, and ethnicity. J Thorac Oncol 4:37-43

11. Yeh AC, Ramaswamy S (2015) Mechanisms of cancer cell dormancy-another hallmark of cancer? Cancer Res 75:5014-5022

Publisher's Note Springer Nature remains neutral with regard to jurisdictional claims in published maps and institutional affiliations. 